\title{
Selected Abstracts
}

\section{for Invited Presentations and Symposia}

\author{
Monday, 13 May \\ 0915-1115
}

\section{Disaster 1: Airport Disasters $406 A$}

\section{Emergency Medical Services in Airport Emergency Planning Auffret, $R$}

\begin{abstract}
Airports are large communities. More than $70 \%$ of aircraft accidents occur on or in the immediate vicinity of an airport. Emergency Medical Services (EMS) at an airport provide: 1) everyday medical treatment and first aid to the airport staff and passengers; and 2) collective emergency services in the event of an aircraft accident. Aircraft may be categorized for the purpose of predicting numbers of casualties anticipated according to passenger capacity: i and ii) 5 to 7 ; iii) 5-7 to 27 ; iv) $27-272$; and v) $>272$. The proportion of passengers who will become casualties decreases as capacity increases: iii) $<45 \%$; iv) $<15 \%$; and $v$ ) $<10 \%$. Thus, the maximum number of persons likely to be injured in an aircraft accident is 100 . Injured victims should be classified into three categories: 1) urgent; 2) serious; or 3) slight. The seriously injured can be subclassified in to three priorities and will occur in the following proportions: I) $20 \%$; II) $30 \%$; III) $50 \%$. Burned and asphyxiated victims will require special equipment and supplies.

The basic principles for planning for an airport disaster include: 1) organize the flow of victims with the establishment of collecting, triage, care, and evacuation areas; 2) organize outer area flow patterns; 3) care for the noninjured; 4) separate the diseased; 5) establish responsibilities; 6) organize a medical command post; 7) provide adequate communications; and 8) organize the dispatch and evacuation of patients. The most important elements are to do the planning, check it, know it, and make it known.
\end{abstract}

\author{
Disaster 2: Health Problems \\ in Evacuated Populations 408AB
}

The Current Approach to Accidents
and Disasters in the Netherlands
De BoerJ

Accidents and disasters are unpredictable in time, nature, magnitude, and location. However, this unpredictability is no excuse for inadequate preparation, especially when evidence exists that the occurrence of disasters is on the increase. This applies not only to cultural disasters that result from the increased intensity of road, sea, and air traffic, and of civil disturbance, but also to natural calamities, such as the more frequent occurrence of storms of increasing intensity, the ever-rising level of the sea, and perhaps increasing tectonic activity.

Progressive medical care of casualties is a concept of aid appropriate to the needs of the individual at any time, beginning at the disaster site and continuing through the transportation and distribution phase to the period of definitive therapy in the hospital. In order to avoid stagnation during this chain of events, synchronization of activities is imperative.

This concept of progressive medical care and capacity in the treatment of casualties after minor and major accidents and disasters in the Netherlands is presented.

\section{Disaster Medicine in the Netherlands De Boer J}

An attempt is made to answer the following questions:

What is a disaster?

Why disaster medicine?

What is disaster medicine?

How is disaster medicine taught in the Netherlands? A simple definition for disaster is presented. Some general reasons, as well as some specific reasons, will be provided to answer the second question relative to the Netherlands. The third question is defined and illustrated by a list of specific topics. The fourth question is answered for the various levels on which Disaster Medicine is taught in the Netherlands. A connection will be sought with the European programme for the teaching of Disaster Medicine, currently being developed by the Scientific Committee of the International Society on Disaster Medicine. 
Toxicology: Street Drugs $410 A B$

\section{Street Drugs \\ Hoffman RS}

It has been estimated that almost 21-million Americans have used cocaine. Approximately 3.5-million are annual cocaine users and are 18-25 years old. It is estimated that there are 65-million life-time and 21-million recent marijuana users including $50 \%$ of high school seniors $(7 \%$ use marijuana daily). In addition, $40 \%$ of the high school senior use other drugs. In 1988 in New York City, there were 690,000 weekly substance abusers (increase of $86 \%$ from 1979 estimates). Substance abuse reached across all socioeconomic and education boundaries including medical students who reported 27,11 , and $10 \%$ used marijuana, cocaine, and tranquilizers respectively and $9.4 \%$ of Boston area college students were substance abusers.

In 1980, U.S. citizens spent [US] $\$ 79$-billion on the purchase of illicit substances, and this amount certainly has increased since. This expenditure is approximately 150 times the combined governmental spending on drug rehabilitation programs or prevention. More recently, emphasis has been placed on drug enforcement (\$10-billion in 1987).

This lecture will discuss some of the basic pharmacology and toxicology of cocaine, phencyclidine, amphetamine, and designer drugs followed by a detailed discussion of the effects these agents have on the health care system. An emphasis will be placed on the current cocaine epidemic.

\section{Auto- and Hetero- Inflicted Chemical Weapons in Europe Bismuth C}

Chemical Intoxicants-Drug addiction represents an autoinflicted chemical aggression. In Western Europe, alcohol still is the best represented form of chemical abuse. Advertising bans for alcohol products in the mass media have increased. In Eastern Europe, the ingestion of illegal ethanol, contaminated with ethylene glycol is increasing; it produces a mortality of $35 \%$ in countries such as Poland. Methanol: its risks of producing deaths is $20 \%$ and of blindness is $10 \%$. It also has been involved in these incidents of auto-inflicted chemical aggression.

Cannabis has no significant, recognized role in hospital admissions, or in abnormal behavior in the streets. Heroin is responsible for robberies (mostly in pharmacies and drug stores), violent behavior, and remains the primary cause of "pseudo-sudden" death in young adults. Studies indicate that $55 \%$ of the users of intravenous (IV) heroin are HIV-positive. Most of the addicts are changing their route of ingestion from IV use to sniffing. A new analgesic drug, Buprenorphine, has become popular among the addict population in France; it is one of the few opiate-derived analgesics that is active through the oral route. Cocaine and "crack," a smokable cocaine derivative, are not yet mass-consumed drugs in Europe.
Amphetamines are used more for their anorectic effect than for enhancing physical and intellectual capacity. The use of "Ecstasy," an illicit drug that induces acute psychosis with paranoid delusions, also has been reported. The consumption of benzodiazepines has given rise to some well-documented street troubles, such as thefts, and sexual or financial submission.

Chemical Weapons-Chemical weapons have been feared in Europe during these past few years because of the threat of widespread terrorism. The effect of these weapons has been observed in European hospitals when civilians and soldiers were transferred there for treatment from Iran and Iraq. Both anticholineasterase agents and mustard gas were involved. The toxicity of nerve gases (Tabun, Sarin, Soman) is similar to the effects of poisoning with organo-phosphate insecticides with two specific effects-rapid onset of the physical effects of poisoning (often within seconds of exposure) and difficulty in regenerating the "aged" enzyme.

Mustard gas actually is a liquid which accumulates on the clothes and causes delayed cutaneous exfoliation, respiratory ulcerations and possible obstruction, and conjunctivitis. The skin takes on a brownish color due to the hyperactivity of melanocytes in the epidermis. Marrow aplasia is possible as well. Mustard gas and its metabolite, thiodiglycol, can be found remaining in the blood for more than 15 days, and it has a strong mutagenic effect.

\section{Pediatrics: Acute Respiratory Distress $401 A B C$}

\section{The Child With Acute Asthma Rubin B}

All that wheezes is not asthma and all that is asthma does not wheeze. Infections like RSV bronchiolitis can mimic asthma. Bronchiolitis can be considered a variant of asthma in terms of pathophysiology, family history, and to some extent, in the response to asthma medications. Except for Mycoplasma and possibly chalmydia pneumoniae (formerly TWAR variant) that have been demonstrated to precipitate asthma attacks, bacterial pneumonia is uncommon in children with asthma.

Airways obstruction can be due to extrinsic compression by the heart, lymph nodes (e.g., TB), blood vessels, inspissation of mucus, or aspiration of food or a foreign body. Unusual causes of obstruction include tumors (but not thymus), bronchomalacia, or tracheomalacia. Airways damage such as bronchopulmonary dysplasia, suction catheter trauma, or hydrocarbon aspiration can lead to stenosis and wheezing with variable responses to bronchodilators. Although half of the children with cystic fibrosis also have increased airway reactivity, they rarely present initially with acute asthma. In cardiac failure, the other signs and symptoms are so prominent as to not be easily missed. Psychogenic asthma is more common in a patient known to have true asthma and should be considered in mild- to moderately-ill children with "unrespon- 
sive" asthma. This is not the same as asthma precipitated by emotions: a form of exercise induced asthma.

\section{Management of Near-Drowning and Hypothermia in Children \\ Li MM}

Drowning causes significant morbidity and mortality in children. In spite of different medical therapies, drowning seems to be an all-or-nothing condition: if vital signs are present on admission to the emergency department, the patient will survive neurologically intact. Spontaneously breathing patients who require assisted ventilation or who have alarming histories (prolonged immersion, apnea, cyanosis), abnormal physical examination or laboratory studies should be observed in the hospital for at least 24 hours.

Hypothermic drowning has been reported to have better survival in some cases. In such cases, resuscitative efforts should be continued until the patient's core temperature is $>30^{\circ} \mathrm{C}$. If any impact is to be made on this common childhood tragedy, prevention strategies must be developed and lobbied politically.

\section{Monday, 13 May \\ 1400-1600}

\section{Trauma: Treatment of Shock $406 B C$}

\section{Small Volume Resuscitation: Hypertonic Saline Dontigny L}

Small volume resuscitation with hypertonic saline is an attractive modality, but still is at an early stage of experimental and clinical investigation. Aggressive resuscitation from traumatic, hypovolemic shock could be facilitated during the prehospital phase, but hypotension remains a physiological and beneficial compensatory mechanism to minimize active bleeding until definitive care is achieved. Despite encouraging results, we cannot conclude at this time, that hypertonic saline is a truly magic potion.

\section{Toxicology: Cardiotoxic Drug Overdoses $410 A B C$}

\section{Theophyllin Intoxication Gaudreault $P$}

The pathophysiology of theophyllin intoxication is presented. The hemodynamic effects are dose-dependent: low-dose induces increased cardiac output and total peripheral resistance; high-dose stimulates Beta-2 receptors and a decrease in peripheral resistance. The CNS stimulant effects are thought to be related to the blockade of adenosine synthesis. Hyperglycemia is mediated by release of catecholamines and hyperkalemia from the shift of intracellular $\mathrm{K}+$ due to the hyperglycemia and Beta-2 stimulation. The clinical manifestations include arrhythmias which are both concentration and agedependent. Neurotoxicity is dose- and age-dependent and depends on the acute or chronic nature of the ingestion. Treatment includes the prevention of absorption which may include induction of vomiting or gastric lavage (debated), administration of activated charcoal (very effective), and/or cathartics (Sorbital); or whole bowel irrigations; enhancement of elimination using hemoperfusion or dialysis (forced diuresis not useful); and supportive care through control of seizures (diazepam and phenobarbital, but not phenytoin) and control of arrhythmias (propranolol).

\section{Task Force 1: International Cooperation and Help $409 B$ (continued on Tuesday 14 May) Rottman SJ (Chair)}

In keeping with the charge to the Task Force, a working group of collaborators from several organizations has been convened to investigate the composition of urgent medical response teams which might be called upon to assist local authorities with immediate medical care following a catastrophe. The participants agreed that it would be most valuable for national disaster planners to know that such response teams are composed and equipped similarly.

An attempt has been made to gather and collate descriptive information from several organizations concerning equipment and medication inventories, team composition, and transportation capabilities. The working committee also solicited information about the assembly and storage of equipment, where it is kept, how it is maintained, and the rotational resupply of perishable items. Mechanisms used for basic training respective to their roles in disaster response medicine and for briefing prior to arrival at the scene were studied. Finally, issues relative to financing were addressed.

In a preliminary review of the operations of the Japanese, Israeli, and Swiss teams, the International Red Cross, and the National Disaster Medical System response in the USA, several principles emerged which seem universal. Differences in style, funding sources, and operational techniques also seem apparent. The sessions will stress the details of team composition and medical supplies, and the logistics of accessing and transporting the response teams. It is the goal of these sessions to reach consensus on the composition and operations of rapid deployment medical aid teams which can be mobilized in a matter of hours. 
Tuesday, 14 May

0915-1115

\section{Trauma: Airway $406 B C$}

\section{Airway Management for the Trauma Patient Grande CM}

In recent years, there has been renewed interest in the management of trauma patients by anesthesiologists within the United States. In trauma centers, emergency departments and prehospital service systems, the anesthesiologist is playing an increasingly active role in trauma care. Along with this renewed interest has come reexamination of techniques for airway management for the seriously injured patient. Simultaneously, developments in pharmaceutical agents, equipment, and refinements in clinical techniques have occurred. The topics to be discussed in this context will include: 1) the use of nasotracheal versus orotracheal intubation with manual, in-line cervical spine immobilization. Pros and cons exist for each option and individual opinions vary greatly; and 2) the use of depolarizing versus non-depolarizing muscle relaxant (i.e., succinylcholine) is considered.

\section{The Laryngeal Mask Airway Brain AIJ}

The Laryngeal Mask (LM) is a new airway adjunct which forms a low pressure seal around the laryngeal inlet when inserted blindly into the pharynx. It provides a clear airway which permits gentle positive pressure ventilation. The design avoids the dangers of lung barotrauma, laryngeal trauma, accidental one-lung occlusion, and oesophageal placement. With simple training, it can be inserted within a few seconds. Insertion does not require a laryngoscope or muscle relaxants and may be performed blindly in any patient position provided the mouth can be opened and reflex responses are depressed sufficiently. Once inserted, it is tolerated exceptionally well and normally will not be rejected until the protective reflexes are restored. The dangers of attempting removal when the patient reacts adversely to a surgical stimulus due to anesthesia or removal before recovery of protective reflexes must be emphasized. Unlike with an endotracheal tube, effective coughing can occur with the device in situ. It is possible to intubate the trachea blindly through the LM, using it as a guide. It also is possible to pass a large-bore tube behind the LM into the oesophagus or to perform flexible gastroscopy using a full-size gastroscope without dislodging the device or losing the seal against the laryngeal inlet.

Because LM does not penetrate the laryngeal inlet, it often is remarkably easy to insert in patients who are known to be difficult or impossible to intubate. Unless the recommended insertion technique is scrupulously followed, difficulties may be encountered in passing it smoothly behind the back of the tongue and in avoiding downfolding of the epiglottis, and these problems can occur in patients who are easy to intubate.

The LM does not prevent regurgitation and was developed for routine use in fasting surgical patients. However, the speed and simplicity of insertion allows rapid correction of hypoxia and upper airway obstruction and reduces the risk of regurgitation. Paramedical personnel can be trained to use the device. It is estimated that the device has been used successfully during anesthesia in more than 2-million patients in the two years since it became available and that it is being used in $90 \%$ of the general hospitals in the United Kingdom. There now are more than 95 publications documenting its use and effectiveness.

\section{Toxicology: Antidotes 410BC}

\section{The Uses of Flumazenil in the Treatment of Drug Poisoning L'Heureux $P$}

Flumazenil is an imidazobenzodiazepine derivative which is an antagonist ligand for central benzodiazepine (BZD) receptors. A large clinical experience now exists relative to its effectiveness in the reversal of BZD and BZD-like compound induced sedation. It also has been useful in the treatment of paradoxical reactions to BZD. Its value in the treatment of ethanol-induced coma, carbamazepine poisoning and hepatic encephalopathy still is controversial.

In order to avoid too sudden or complete arousal, Flumazenil administration must be meticulously titrated by slow IV injection. The half-life is short and continuous infusion may be required. Other precautions must be followed such as prevention of absorption of the offending agent and repeated clinical evaluations. The antidote should not be used to hasten psychiatric evaluation.

It may also be useful as a diagnostic tool for coma of unknown etiology. Lack of improvement within a few minutes following IV administration of 1-2 $\mathrm{mg}$ flumazenil excludes $\mathrm{BDZ}$ as a determining cause of the coma. Conversely, fast and persistent or reproducible awakening demonstrates the implication of BZD or BZD-like compounds as a component of the cause of the coma, and often permits interrogation of the patient relative to ingestion of other agents and may help to avoid toxicologic screening. Improvements following flumazenil administration has been reported following ethanol or carbamazepine intoxication, hepatic encephalopathy, and even post-anoxic coma. The mechanism for improvement in these conditions remains poorly understood.

The agent seems safe, and it is well-tolerated. Several side effects, it may precipitate acute withdrawal symptoms in chronic BZD users, and could precipitate the effects of concurrent overdoses of other compounds. Transient increases in intracranial pressure in head injury victims have been noted. 
Tuesday, 14 May

$1400-1600$

\section{Toxicology: Decontamination $409 \mathrm{~A}$}

\section{Issues and Controversies \\ Vicas I}

Gastric decontamination has been a key component of management of overdose patients for decades. Over the years, a variety of methods to be used either alone or in combination have been advocated and debate has raged relative to the superiority of one over the other. These methods include: 1) Ipecac administration; 2) Gastric lavage; 3) Activated charcoal; 4) Cathartics; and 5) Whole bowel irrigation. However, more recently, the question of "is gastric decontamination really necessary?" has been posed. A review of experimental data comparing these techniques will be presented.

\section{Whole Bowel Irrigation in Poisoned Patients Teninbein $M$}

Prevention of absorption is a primary goal in the treatment of the acutely poisoned patient. The traditional approach is through the use of a gastric emptying procedure with syrup of ipecac induced emesis or Gastric lavage followed by the administration of activated charcoal. Recent research has cast doubt upon the use of these socalled gastric emptying procedures, and activated charcoal is being touted as the primary gastric emptying procedure. However, situations arise where even charcoal would be expected to be of limited benefit. These situations include the ingestion of a very large amount of a toxic substance i.e., many times the lethal dose), late presentation, ingestion of a modified release form, and ingestion of a substance not adsorbed by activated charcoal (particularly iron). Whole bowel irrigation (WBI) may have a role in some of these situations.

Whole bowel irrigation is a routine preparative procedure. It consists of the rapid enteral administration of large volumes of a specialized lavage fluid to irrigate the contents out of the gastrointestinal tract. Generally, the lavage fluid is a polyethylene glycol, electrolyte solution specifically formulated to prevent any net absorption or secretion of fluids or electrolytes across the gastrointestinal epithelium. This summary reviews the use of WBI as a gastrointestinal decontamination procedure.

The following advice is offered: 1) avoid pre-treatment with ipecac because after its administration, WBI may not be tolerated; 2) use a nasogastric tube for irrigation administration; 3) activated charcoal may be administered prior to initiation of $\mathrm{WBI}$; 4) a commode is convenient; 5) IV administration of metoclopramide may be required to control ingestant induced vomiting; 6) irrigation rates should be $2 \mathrm{~L} /$ hour for adults and $.5 \mathrm{~L} /$ hour for toddlers and preschoolers. The end-point is achieved when the rectal effluent is similar in appearance to the infusate. Usually, this takes several hours.

Studies and clinical experience with WBI establish it as an effective intervention for overdose patients. However, it is not a panacea, and it should not be considered as a primary gastrointestinal decontamination procedure. It is both labour intensive and time consuming, and it should be considered only in the specific situations outlined.

\section{Trauma/Pediatrics: Blunt Abdominal Trauma; Airway Management; Resuscitation $401 A B C$}

\section{Pediatric Abdominal Trauma \\ Luks FL}

The abdomen is involved in $9-17 \%$ of children with multiple injuries and tends to be blunt and insidious. It may be overlooked because of more spectacular, associated injuries, head injuries may obscure its presence, and children may be difficult to examine. The prompt and accurate diagnosis depends upon a high index of suspicion, an understanding of differences between children and adults and of the mechanism of pediatric trauma, and on reliable diagnostic tools such as computerized tomography and ultrasonography.

The specifics of each of these problems will be discussed in detail. In addition, the implications for treatment will be defined. Proper management of pediatric abdominal trauma aims at stabilization of the child and identification of those injuries which will require immediate surgical intervention. Only then can the patient be triaged to the intensive care unit, the ward, or the radiology department, and a more precise diagnostic workup undertaken.

\section{Cardiology: Cerebral Resuscitation $411 A B$}

\section{Survivors of Cardiac Arrest: Is There a Role for Antiarrhythmic Drugs? Welsh WJ}

Sudden cardiac death continues to be a challenge to physicians involved in resuscitative efforts and for cardiologists involved with the long-term management of the survivors. Following cardiac arrest, those patients who did suffer a myocardial infarction remain at high risk for recurrences and therefore, require chronic preventive therapy. In the past, therapy was limited largely to the use of antiarrhythmic agents, but the advent of the implantable cardioverter-defibrillator provides another option. Given the side-effects and limited efficacy of the pharmacologic agents, the continuing role of the antidysrhythmic drugs in this setting must be questioned.

When the risk of recurrent episodes of ventricular arrhythmias in survivors of sudden cardiac death, the toxicity of the antiarrhythmic drugs, and the protective effects 
of the implantable defibrillator are considered, the implantable defibrillator would seem to be an early choice in the treatment of such patients. Despite the expense of the device and the procedure for implantation, the device appears to be cost-effective, particularly when implanted early in the course of evaluation. Patients with implanted defibrillators will have lower rates of readmission for recurrences and probably lower rates of side effects and toxicity from antiarrhythmic agents. Given these factors, survivors of cardiac arrest should be evaluated carefully for the risk of recurrence, including cardiac catheterization with coronary angiography and electrophysiology studies. Patients at high risk should have early consideration for implantation of an automatic defibrillator system.

\section{Wednesday, 15 May \\ 0915-1115}

\section{Transplantation: Organ Procurement and Ethics $410 \mathrm{ABC}$}

\section{Organ Donor Management \\ Gelb AW}

This discussion examines donor identification, declaration of brain death, and the management of the donors. The principles of management of specific problems of the donor including hypotension, arrhythmias, diabetes insipidus, oliguria, electrolyte imbalance, hyperglycaemia, respiratory failure, hypothermia, and anaemia and coagulopathy is outlined.

\section{Cardiology: Cerebral Resuscitation $411 A B$}

\section{Cerebral Resuscitation: Current and Future Research SafarP}

Cardiac arrest reversed by cardiopulmonary-cerebral (CPCR) resuscitation includes temporary, complete, global brain ischemia. Treatments effective after cardiac arrest may or may not be effective in cases of shock (temporary incomplete global ischemia), stroke (incomplete focal ischemia), or head injury. This paper discusses "resuscitation" (treatment to reverse cardiac arrest and support recovery by mitigation of the secondary, post-resuscitation syndrome), and not "protection" (treatment before the insult), and not "preservation" (treatment during the insult). Reproducible, prolonged cardiac arrest animal models should include post-arrest life support to 3-7 days, with control of temperature and other variables. Control therapy should result in survival with brain damage.
The current status of reflow promotion, barbiturate loading, administration of calcium blockers, hypothermia, and cardiopulmonary bypass, will be discussed. Those interventions which have not produced positive results consistently including the administration of an excitatory neurotransmitter receptor blocker, anti-free radical cocktails, lidocaine, and attempts at detoxification using gut washout, antibiotics, or hemabsorption will be examined. The current status of the use of the aminosteroid, Lazaroid, will be discussed.

Multifaceted treatment using hypothermia plus drugs and other measures still are to be worked out in order to achieve consistent reversal of the effects of 10-20 minutes of no flow.

\section{Improved Recovery with 21-Aminosteroid (U74006F) Pre-Treatment after Complete Cerebral Ischemia Traystman $R J$}

The 21-aminosteroid, tirilazad (U74006F), inhibits lipid peroxidation in vitro. The ability of this agent to improve immediate recovery from global, incomplete, cerebral ischemia produced by intracranial hypertension was examined. Methods: Two groups of anesthetized dogs were studied: Vehicle group (citrate buffer, $n=8$ ); and the Drug group $(1 \mathrm{mg} / \mathrm{kg} 20$ minutes prior to ischemia plus 0.18 $\mathrm{mg} / \mathrm{kg} / \mathrm{hour}, \mathrm{n}=8$ ). Ischemia was produced by ventricular infusion of warmed artificial CSF to decrease cerebral perfusion pressure to $10-15 \mathrm{mmHg}$ for 30 minutes.

Results: Cerebral blood flow, measured with radiolabeled microspheres, decreased $80 \%$ to $6+1 \mathrm{ml} / \mathrm{min}$ / $100 \mathrm{~g}(+\mathrm{SE})$ in both groups. Intracellular $\mathrm{pH}(\mathrm{pHi})$ measured by $131 \mathrm{P}$ magnetic resonance spectroscopy, decreased from a mean value of $7.09+0.03$ to $6.09+0.07$ with the vehicle and from $7.04+0.03$ to $5.93+0.08$ with the drug. Upon cessation of the CSF infusion, pHi recovered significantly faster with the drug $(15+3$ minutes) than with the vehicle $(31+5$ minutes). Recovery of somatosensory evoked potential amplitude was significantly greater with the drug $(49+5 \%$ of control than with the vehicle $(32+6 \%)$. At three hours of reperfusion, fractional water content of cortical grey matter was significantly less with the drug $(0.819+0.003)$ than with the vehicle $(0.831+$ 0.002 ). Cerebral O2 consumption and ATP recovered fully in both groups.

Conclusions: These data indicate the 21-aminosteroid pretreatment results in improved rates of brain $\mathrm{pHi}$ during reperfusion despite equivalent severity of ischemia and acidosis during intracranial hypertension. Moreover, rapid $\mathrm{pHi}$ recovery is associated with less edema and greater evoked potential amplitude. Lipid peroxidation may contribute to the injury with this severity and duration of ischemia.

*Supported by NS20020 
Task Force 1: International Cooperation and Help $409 B$ Rottman SJ, Pretto E (Chair)

\author{
Basic Extrication Training of the \\ Lay Public for Disaster Preparedness \\ Abrams J, Pretto E, Angus D, Safar P
}

It has been suggested from retrospective studies that lives can be saved by rapid, efficient Basic Extrication (BE) and Life-Supporting First Aid (LSFA) within 24 hours after a disaster. It is proposed that the most effective way to achieve a quick response is by utilizing the local, uninjured population trained in LSFA and BE. Formal responders rarely are on the scene as quickly as are co-victims who often have detailed knowledge of the location of the entrapped victims. In addition, novel equipment is needed for the second phase (heavy rescue). Populations in regions of high seismic risk (often lack response resources) should be taught LSFA and BE. Such a course is indicated.

A course which could train lay persons to provide such procedures using elementary or improvised tools is proposed. It would include basic survey techniques, responder safety, patterns of building collapse/damage, and methods to access victims. Techniques suitable for different damage patterns, rubble removal, and shoring would be emphasized. The importance of access to victims for LSFA before and during extrication would be stressed. Training in BE must be integrated with LSFA.

\section{Life-Supporting First Aid Training of Lay Public for Disaster Preparedness Angus D, Pretto E, Abrams J, Safar P}

The feasibility of training lay persons in Life-Supporting First Aid (LSFA) including cardiopulmonary resuscitation (CPR) has been recognized for some time. In addition, it has been suggested that, in earthquake prone regions, general public knowledge of LSFA and Basic Extrication (BE) may have significant life-saving potential. Therefore, the widespread training of both LSFA and BE to these populations must be encouraged and coordinated.

To minimize confusion, LSFA guidelines should be based on existing first aid techniques. Eight LSFA techniques which do not conflict with Red Cross teaching are recommended: 1) scene survey-rescuer safety, assessment of entrapment, need to access head; 2 and 3) airway control-airway tilt and mouth to mouth breathing with protection from dust inhalation; 4) circulation-c hest compressions have low relevance and effectiveness; 5) abdominal thrusts for choking can be omitted; 6 and 7) control of bleeding and positioning for shock-most important; and 8) call for help-including BE. Emphasis must be placed on care of the trapped victim which includes early access to the airway, but, if possible, delay of the release of crushed body parts until advanced life support is available.
Wednesday, 15 May

1400-1600

\section{Disaster: Communications, Command, and Cooperation $401 \mathrm{ABC}$}

\section{Characteristics of the Medical \\ Front Post in Civilian Disaster \\ Julien H, Fontaine $P$, Menage $P$}

Each year, our firemen of Service Medical d'Urgence (SAMU) render first aid to citizens. The 45 physicians of the fire brigade teach the firemen and provide medical control. In addition, they deliver advanced CPR or therapy 10,000 times a year.

In the case of a catastrophic event, the organization of immediate rescue and treatment is composed of two sections: the red plan, and direction by a physician called the medical rescue director. The red plan provides the means and the personnel to accomplish the three missions of medical rescue: picking up; sorting and resuscitation; and evacuation to a hospital.

The place where the injured are gathered to be examined, triaged, and treated is called the medical front post. In the early days of the program, the injured were gathered in a church, school, train station, airport, or most often in a cafe. Subsequently, specific equipments have been developed which differ substantially from those used at a military front post. The delays for the system to become operational are very short. Modules which are air inflated have been placed in four main stations. The time required for transport and inflation is about 20 minutes. Since manpower is limited early in such an event, light air tents were selected which require only five persons to erect. This task for each usually can be completed in about five minutes. It is modular and can be organized by the medical rescue director for greatest efficiency and can be adapted readily to include other modules from SAMU and the Red Cross. It has one entrance (triage area), one exit (evacuation point) and two treatment areas. Medical equipment is transported by a specialized vehicle and is grouped functionally: cardiovascular; respiratory, and immobilization.

The medical front post is organized into two zones which allow for maximum efficiency: 1) Absolute emergency $(\mathrm{AE})$ for those in need of resuscitation and therapy; and 2) Relative emergency (RE) in which the lightly wounded are gathered. Neither an operating room or hospital beds are necessary.

In a disaster medical front post, the wounded are evacuated promptly to hospitals. Few surgical procedure are required except for stopping hemorrhage or evacuation of a hemo- or pneumothorax.

This method has been used successfully to provide care for the victims of civilian disasters. 


\section{Cardiology: High Dose Alpha Agonist Therapy in Cardiac Arrest $411 \mathrm{AB}$}

\author{
Adrenergic Drug Therapy \\ in Cardiopulmonary Resuscitation \\ Brown CG
}

Post-synaptic alpha-1 and alpha-2 receptors mediate vasoconstriction. During ischemia, post-synaptic alpha-2 receptors may have a more significant contribution to vasomotor tone than do the alpha-1 receptors. Epinephrine and norepinephrine have a post-synaptic alpha-1 and alpha-2 post-synaptic agonist activity while phenylephrine and methoxamine have alpha-1 activity. During cardiac arrest, epinephrine and norepinephrine levels are elevated significantly. However, despite the elevated levels of circulating endogenous catecholamines, myocardial and cerebral blood flow are poor. This is complicated by apparent development of tolerance at the alpha receptors. This tolerance may explain a need for increasing doses catecholamines.

The use of epinephrine $(0.2 \mathrm{mg} / \mathrm{kg})$ and norepinephrine $(0.12-0.16 \mathrm{mg} / \mathrm{kg})$ have been shown to improve hemodynamics during CPR and resuscitation rates in animals. Clinical studies regarding the effectiveness of epinephrine and other alpha agonists in the treatment of victims of prehospital cardiac arrests remain inconclusive. Current research studies and the need for additional studies will be outlined.

\section{Wednesday, 15 May}

1400-1700

\section{Symposium: Workshop on Early Defibrillation Using Automated External Defibrillators $411 C$ Cummins RO, Hearne TR, Graves JR, Norton J, Smith B, Brooke D}

Early defibrillation has been established as the key intervention for successful resuscitation of people in sudden cardiac arrest. Automated or "smart" defibrillators have become a major breakthrough in the provision of early defibrillation. Emergency Medical Systems across the globe have started early defibrillation programs using smart defibrillators. The American Heart Association (AHA) has endorsed the principle of early defibrillation. This concept states that all Basic Life Support personnel should be trained to operate, equipped with, and permitted to operate a defibrillator. To encourage adoption of this principle, the AHA recently has developed educational materials for early, automated defibrillation. This material has been presented in workshops across the United States, and now is included in all AHA-ACLS courses.

The faculty for this workshop have participated in the development of the AHA-Automated External Defibrillator (AED) materials. They have conducted numerous workshops for starting and maintaining an early defibrillation program using smart defibrillators.
The three hour workshop will cover: 1) rationale for early defibrillation; 2) the EMS concept (chain of survival); 3) the devices and their operation; 4) standing orders and field protocols; 5) class organization and conduct; 6) evaluation; and 7) program maintenance. The workshop will use a small group teaching approach. Attenders will be assigned into small groups and will rotate between topics. Each will obtain hands-on experience with each of the currently available smart defibrillators, and will have an opportunity to practice field protocols. Open discussion, problem-solving, and questions will be encouraged.

\section{Wednesday, 15 May $1630-1800$}

\section{Disaster: Table Top Simulation $410 A B C$}

\section{Table-Top Simulation for Mass Casualty Training Donchin Y, Adler J}

A mass casualty drill is expensive. The cost of a simulated explosion exercise held in Jerusalem in 1989, was [US] $\$ 400,000$. The purpose of the conduct of a drill is to gain some answers to some basic questions concerning preparations for such an event.

The authors have implemented an old method of the table-top exercise to help to provide some answers to such questions. The simulation is based on the meticulous preparation of a scenario unknown to the participants. The drill is carried out in a large room so that all delegates representing the various agencies can participate and interact. A large map of the area or a model of a building is presented to the audience. The scenario is presented with the aid of two slide projectors. In order to analyze the events in detail, the times are frozen according to the time table of the event. The moderators ask questions or add unexpected problems. This drill usually takes four hours. The first two hours are dedicated to the first 20 minutes of the event. In the next two hours, the participants deal with the after-effects: triage of the wounded; media; social organization; etc. The cost of such an exercise is around [US] $\$ 1,000$. As an illustration, a scenario of a bomb explosion in Tel Aviv will be presented.

\section{Symposium: Education $408 C$ Pre-Graduate Training in Emergency Medicine}

\author{
Emergency and Disaster Medicine: \\ Undergraduate Training \\ Dick $W$
}

Undergraduate education in Emergency Medicine has been promoted extensively in recent years. However, it is unfortunate that Disaster Medicine has been a controversial topic, particularly from the perspective of possible nuclear disasters. Currently, a more objective discussion 
is taking place relative to disaster preparedness.

Undergraduate education in Emergency and Disaster Medicine recently has been redesigned in such a way that medical students are required to take three different courses on the subject: 1) eight credit hours in basic CPR, eight credit hours in first aid, and if possible, refresher courses during the pre-clinical part of the training period. This training has to be taken at the university, the Red Cross, or a similar institution; 2) basic Emergency Medicine taken after the completion of the first third of the medical education program; and 3) practical skills, intensive care medicine, and practical experience on the Mobile Intensive Care Unit (MICU).

The second section consists of a total of 30 credit hours to be completed within 10 weeks and should provide the undergraduate with practical and theoretical knowledge in clinical death, restitution of vital functions, acute respiratory disturbances, acute cardio-circulatory disturbances, coma, acute CNS disturbances, and special aspects such as burns, near drowning, polytrauma, etc. The thirty credit hours are subdivided into a lecture program of 10 lessons, and a practical consisting of 20 credit hours.

Just recently, a third part has been introduced into the undergraduate training program. This 36 -hour course is taken during the last third of the education program. A generally accepted course structure has not been agreed upon. This course was organized similarly to the course for medical students and rotating residents described by Shepard et al in 1990. The course is to be taken over a 12week period and is subdivided into 10 credit hours of lectures covering patients with dyspnea, polytrauma, thoracic pain and several other topics. A second 10-hour segment concentrates on the discussion of actual emergency situations experienced by the emergency physician and reported to small groups of students.

In the third part of the course, each student receives 16 hours of instruction, subdivided into two, 8-hour segments covering endotracheal intubation and venous cannulation in the operating theater, treatment of severely injured patients in the intensive care unit, and out-ofhospital emergency operations supervised by emergency physicians in the MICU. The latter part includes a twohour training period under megacode conditions.

Future aspects of the undergraduate training program for Emergency and Disaster Medicine will be discussed.

\section{Pre-Graduate Trauma Education \\ Donchin Y, Kluger Y, Reokind A}

A few weeks after graduation from six-years of medical training, the new Israeli physician has to face trauma cases on the battlefield and on the highway. The objectives regarding trauma education are to enable to a new doctor to be skilled and knowledgeable in treatment of traumatically injured patients.

The trauma education program extends over the six years of medical training. A new topic is introduced each year: basic first aid in the first year, basic life support in April-June 1991 the second year, and advanced cardiac life support in the third year. As an obligation to society, the students must serve at the ambulance station in Jerusalem for at least one shift, twice each month. In this way, they are exposed to emergency situations.

During the clinical fourth and fifth years, trauma topics are stressed during anesthesia and surgery rotations. As a summary of all of these efforts, a two-week, integrated course takes place during the final year. The culmination of this course includes a mass-casualty drill in Jerusalem. Students serve as wounded patients, and ambulances transfer them from the streets to the participating teaching hospitals. The simulated wounded evaluate the first aid they receive, the method of transfer, and their treatment at the admission area of the hospital. The drill is videotaped and analyzed later by the students.

A video of the drill is presented.

\section{Thursday, 16 May}

0915-1115

\section{Education: Post-Graduate Training in Emergency Medicine 408C}

\section{Postgraduate Emergency Medical Training in Japan Ukai $T$}

There are 80 medical universities and 104 life-saving emergency medical centers in Japan. Principally, postgraduate emergency medical education is provided in these institutions. Emergency departments or tertiary emergency centers are located in 69 of these schools, and 45 of them are used for postgraduate emergency medical training. As there is no standard curriculum for this type of training; it is provided according to the institution's own background.

For each of the past 16 years, three-day seminars on Emergency Medicine sponsored by the Japanese Association for Acute Medicine (JAAM) have been attended by between 150 to 200 students. In 1990, the Ministry of Health and Welfare sponsored a 10-day Emergency Medicine Training Course for young physicians who work for the local governmental hospitals, as a means to improve emergency medical services at the community level. The Emergency Medical Board and Instructor System was adopted by JAAM several years ago, and the number of young physicians who want to work exclusively in Emergency Medicine gradually has been increasing in number.

\section{Emergency and Disaster Medicine: \\ Post-Graduate Training \\ Dick $W$}

The present situation in Emergency and Disaster Medicine is characterized by the fact that, in general, training in Emergency Medicine is not a compulsory part of the postgraduate education. However, many

Prehospital and Disaster Medicine 
young physicians are interested in participating in a special Emergency Medicine training program for physicians who want to operate outside the hospital. This training program is subdivided into: 1) prerequisites; 2) theoretical lectures; and 3) practical training.

The prerequisites include one year in clinical Intensive Care Medicine. This should guarantee that the physician interested in practicing Emergency Medicine is able to perform endotracheal intubation, peripheral and central venous cannulation, advanced cardiac and advanced trauma life support, thoracostomy tube drainage, needle thoracostomy, pericardiocentesis, chest pain evaluation, evaluation of the emergency patient, pain treatment, prehospital care, cardiopulmonary resuscitation (CPR), including infant CPR, advanced cardiac life support (ACLS), trauma, shock, respiratory disease, metabolic emergencies, nervous system diseases, repair of lacerations, etc.

The practical third part consists of megacode training and actual emergency operations aboard a mobile intensive care unit (MICU) under the continuous supervision of an experienced emergency physician. Between 10 and 20 prehospital operations have to be carried out in the setting of life-threatening situations.

This paper will report the future plans for the postgraduate emergency medical course work, prerequisites for applicants, plans for increased training that involves a higher number of prehospital operations, medical control of disasters and mass casualty events by a managing emergency physician, and a description of the training program.

\section{Management: Efficient Language/Casualty Rooms/Wards; Interface between Hospitals and Emergencies $411 C$}

\section{Emergency Department and Hospital Overcrowding: Disaster Management on a Daily Basis Allison EJJr.}

Emergency department and hospital overcrowding increasingly are a widespread phenomenon. Overcrowding is severely limiting the public's right to timely emergency medical care and compromising the quality of that care. Because overcrowding frequently requires that emergency physicians and nurses provide critical care and inpatient management for extended periods of time, fundamental changes in emergency department policies, procedures, and practice style may be needed to facilitate these patient machinations.

The development of realistic and effective contingency plans will allow emergency physicians and nurses to join their patient colleagues, hospital administrators, prehospital providers, and EMS managers to deal with the immediate consequences of overcrowding. These management tools are more than simple coping mechanisms; however, few will produce significant long-term changes in the nature of hospital overcrowding/ED backup.
Emergency departments provide the critically important safety net for our nation's health care system. Unfortunately, at present, our capacity to meet the needs of our patients is being stretched to the breaking point. Long-term resolution of the problem of hospital and emergency department overcrowding will require substantial commitment of societal resources and vision. Successful resolution of this problem will be a monumental task. It is, perhaps, the greatest challenge facing Emergency Medicine today.

\section{Cardiology: New Technical Advances $411 A B$}

\section{Non-Invasive Monitoring of Ventricular Fibrillation Brown $C G$}

I. Estimation of Ischemia Time (Downtime)

A. Rationale

1. Defibrillation studies

2. Defibrillation injury

3. ATP depletion during ventricular fibrillation

B. Methodology (Fourier analysis)

C. Downtime estimation device

II. Non-invasive monitoring of myocardial perfusion

III. Non-invasive monitor-determining when to defibrillate

IV. Development and testing of a "Smart defibrillator."

\section{Smart Defibrillators: Semi-automatic and Automatic Defibrillation \\ Cummins RO}

Over the past decade, scientific and clinical research has produced a steady maturation of our understanding of the most effective interventions for cardiac resuscitation. No single, "most important" intervention for cardiac resuscitation exists. Instead, there must be a well-planned application of a series of actions to achieve maximum survival rates. These interventions have been summarized by the concept of the "chain of survival" - early access, early defibrillation, and early advanced cardiac life support. In can be argued conceptually that these links in this chain focus on early defibrillation: early access and CPR provide support for the patient until a defibrillator arrives, and early advanced life support stabilizes the patient after early defibrillation has eliminated the ventricular dysrhythmias.

The advent of automated or "smart" defibrillators has produced an important breakthrough for the provision of early defibrillation. These devices greatly expand the range of operators who not only provide early $\mathrm{CPR}$, but who can defibrillate the patient.

This presentation will elaborate the rationale for early defibrillation, the background and clinical research related to the use of automatic defibrillators, and a discussion of the recent educational materials produced by the AHA. 

Yes! Please enter my subscription to PDM for:

One year: $\square$ \$78 Institutional $\square$ \$48 Individual $\square$ \$35 Resident/In Training $\square$ \$35 EMT, Paramedic, RN Two year: $\square$ \$148 Institutional $\square$ \$88 Individual $\square$ \$65 Resident/In Training $\square$ \$65 EMT, Paramedic, RN NOTE: "Institutional" defines multiple reader subscriptions, including libraries, hospitals, government agencies, and all private organizations. Individual subscriptions must be paid by individuals

Offer expires 06/30/91

PREHOSPITAL and DISASTER MEDICINE

A quarterly scientific journal for physicians, nurses, paramedics, instructors, administrators and researchers

The official journal of: The National Association of EMS Physicians

The World Association for Emergency and Disaster Medicine

In Association with the Acute Care Foundation and the National Association of State EMS Directors peer-reviewed

Name/Institution

Address

City

$\square$ Bill m

$\square$ Payment Enclosed

For Canadian subscriptions, add $\$ 10$

1 Occupation:

$\square$ Nurse

$\square$ EMT. Paramedic

$\square$ Administrator/Supv./Purch. Agen

Disaster/Civil Defense Planner

$\square$ Other

(Please Specify)

nature

Make checks payable to PDM, P.O. Box 2789, Carlsbad, CA 92018

$314 Z F 7$

\section{Prehospital and Disaster Medicine}

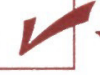

Yes! Please enter my subscription to PDM for:

One year: $\square$ \$78 Institutional $\square$ \$48 Individual $\square$ \$35 Resident/In Training $\square$ \$35 EMT, Paramedic, RN Two year: $\square$ \$148 Institutional $\square$ \$88 Individual $\square$ \$65 Resident/In Training $\square$ \$65 EMT, Paramedic, RN NOTE: "Institutional" defines multiple reader subscriptions, including libraries, hospitals, government agencies, and all private organizations. Individual subscriptions must be paid by individuals.

Offer expires 06/30/91

Name/Institution

Address

City State

Zip

$\square$ Bill me $\quad \square$ Charge my: $\square$ VISA $\square$ MasterCard Exp. Date

$\square$ Payment Enclosed Card\#

For Canadian subscriptions, Signature Date

Make checks payable to PDM, P.O. Box 2789, Carlsbad, CA 92018

314ZF7

Occupation

$\square$ Physician

$\square$ Nurse

EMT Paramedic

Administrator/Sups/Purch Agen

Disaster/Civil Defense Planner

Other

Employment Location:
$\square$ Hospital
$\square$ Fire Department
$\square$ Ambulance Service
$\square$ Regional/State/Federal Agency
$\square$ Industry
$\square$ Other__

Primary Specialty (if Physician)

$\square$ Emergency Medicine

Critical Care

$\square$ Traumatology

$\square$ Prehospital Medical Director

Cardiology

$\square$ Other

(Please Specify)

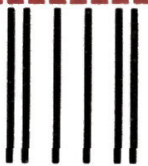

Journal of Emergency

Medical Services

JEMS is the monthly professional trade journal for the emergency medical services industry.

Whether patient care or administration is your focus. JEMS provides you with the news and information you need to stay current with the field.

For over eleven years JEMS has been serving the advanced life support needs of EMTs, paramedics and their instructors and supervisors.
NO POSTAGE

NECESSARY

IF MAILED

IN THE UNITED STATES

\section{BUSINESS REPLY MAIL FIRST CLASS PERMIT NO. 6 SOLANA BEACH, CA}

POSTAGE WILL BE PAID BY ADDRESSEE

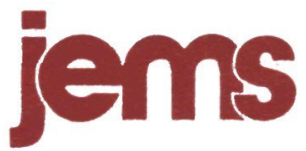

P.O. Box 3730

Escondido, CA 92033-9984 


\section{|||||}

\section{BUSINESS REPLY MAIL FIRST CLASS PERMIT NO. 6 SOLANA BEACH, CA}

POSTAGE WILL BE PAID BY ADDRESSEE

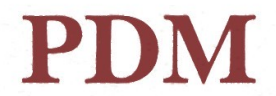

P.O. Box 2789

Carlsbad, CA 92018

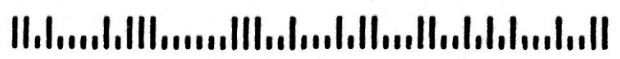

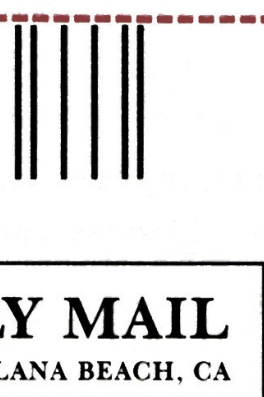

\section{BUSINESS REPLY MAIL \\ FIRST CLASS PERMIT NO. 6 SOLANA BEACH, CA}

POSTAGE WILL BE PAID BY ADDRESSEE

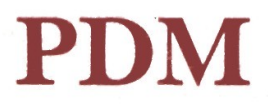

P.O. Box 2789

Carlsbad, CA 92018

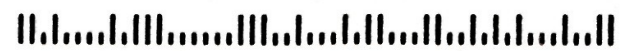

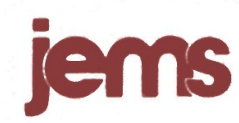

Yes! Please enter my one-year (12 issue) subscription to JEMS for only $\$ 21.97$.

PRINT NAME

\begin{tabular}{llll}
\hline TITLE & ORGANIZATION & & \\
\hline ADDRESS & & & \\
\hline CITY & STATE & ZIP & 314ZE8
\end{tabular}

Make checks payable to JEMS, P.O. Box 2789, Carlsbad, CA 92018

Enclose payment and receive a 13th issue FREE!

$\square$ BILL ME OCCUPATION/POSITION OCCUPATION/POSITION
$\square$ A Phvician

B. Nurse/Inst/Coord

C. Administrator/Supervisor

D. Paramed./EMT./EMT.D

EMT / Basic. 1st Resp

G. Other
EMPLOYER/AFFILIATION

$\square$ 1. Hospital

Private Ambulance

3. Fire Dept/Rescue Squad

4. Third Serv/Mun Ag.

Industrial/Commercia!

Other
This offer expires $08 / 31 / 91$

\section{NO POSTAGE NECESSARY \\ IF MAILED \\ IN THE UNITED STATES}

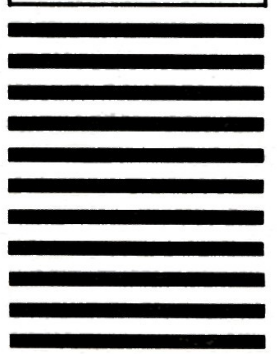

NO POSTAGE

IF MAILED

IN THE

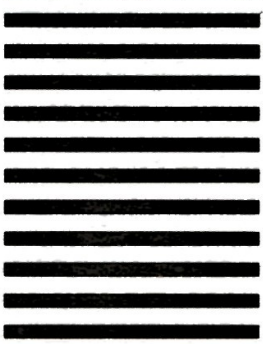

PREHOSPITAL and DISASTER MEDICINE

A quarterly peer-reviewed scientific journal for physicians, nurses, paramedics, instructors, administrators and researchers

The official journal of: The National Association of EMS Physicians

The World Association for Emergency and Disaster Medicine

In Association with the Acute Care Foundation and the National Association of State EMS Directors

\section{JEMS}

Journal of Emergency

\section{Medical Services}

JEMS is the monthly professiona trade journal for the emergency medical services industry.

Whether patient care or administration is your focus. JEMS provi you with the news and information you need to stay current wit the field.

For over eleven years JEMS has been serving the advanced life support needs of EMTs, paramed and their instructors and supervisors. 


\title{
Subscription and Business Information
}

\author{
for the Readers of \\ Prehospital and Disaster Medicine
}

\section{SUBSCRIPTION PRICES}

\section{One-year \\ Two-year \\ (4 issues) \\ (8 issues)}

Institutional $\ldots \ldots \ldots \ldots \ldots \ldots \ldots \ldots \$ 78 \ldots \ldots \ldots . \$ 148$

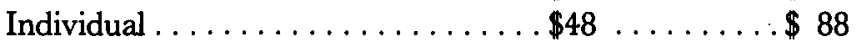

Resident/In Training . . . . . . . . . .\$35 . . . . . .\$ 65

EMT/Paramedic/Nurse . . . . . . . \$35 .......\$65

Note: "Institutional Subscribers" are defined as multiple reader subscribers and include public and private libraries, schools, hospitals and clinics; city, county, state, provincial and national government bureaus and departments; and all commercial and private institutions and organizations.

Individual subscriptions and all student-rate subscriptions must be in the name of, billed to, and paid by individuals. All studentrate requests must indicate training status and name of institution.

Send U.S. subscription orders to: Jems Publishing Company, ?DM, P.O. Box 2789, Carlsbad, CA 92018; 619/431-9797; FAX: \$19/431-8176.

\section{INTERNATIONAL SUBSCRIPTIONS}

International subscription orders should be directed to : Jems Publishing Company, P.O. Box 2789, Carlsbad, CA 92018; telephone: 619/431-9797; FAX: 619/431-8176. Canadian subscribers add $\$ 10$ per year for postage and handling. Please include payment in U.S. funds. All other international subscribers add $\$ 20$ per year.

\section{CHANGE OF ADDRESS \& MISSING ISSUES}

Please let your subscription representative know as soon as possible when you plan to move. We need four to six weeks advance notice for uninterrupted service. Send us your 1) current mailing label (with old address), 2) your new address and 3) effective date of change. If you did not receive an issue, let us know within three months of cover date.

If you have other questions about your subscription, please address them to: Customer Service, Jems Publishing Company, P.O. Box 2789, Carlsbad, CA 92018.

\section{EDITORIAL INFORMATION}

Please address all manuscript and editorial inquiries and comments to: Marvin L. Birnbaum, Editor, Prehospital and Disaster Medicine, 1552 University Ave., Rm. 434, Madison, WI 53705; 608/263-2069 or 608/263-7094; FAX: 608/263-2069.

\section{ASSOCIATION CONTACTS}

National Association of Emergency Medical Services Physicians, Executive and National Resource Center, 230 McKee Place, Suite 500, Pittsburgh, PA 15213; 1-800/228-3677.

World Association for Emergency and Disaster Medicine, Dr. Peter J.F. Baskett, President, Dept. of Anaesthesia, Frenchay Hospital, Bristol BS 16 1LE, United Kingdom.

Acute Care Foundation, P.O. Box 90193, Lakeland, FL, 33804$0193 ; 813 / 539-7352$

National Association of State EMS Directors, Council of State Governments, P.O. Box 11910, Lexington, KY 40578-1910; 606/252-2291.

\section{JEMS-Your Monthly Guide to EMS}

JEMS was created over 11 years ago with one goal in mind: to provide the top men and women of EMS with a monthly journal that would serve them as well as they serve their patients. Publisher Jim Page has been involved in EMS for more than 30 years as a rescuer, administrator, attorney, lecturer and writer. He designed a journal that would feature lively writing and graphics to match the dynamic growth of the EMS industry.

\section{You'll find in JEMS:}

- Continuing Education articles based on case studies of actual prehospital calls.

- "Tricks of the Trade" to enhance your patient care skills.

v Up-to-date news on the people and events that affect your job..

- A yearly salary survey of all EMS personnel-how does your department compare?
Comprehensive information resources on all aspects of EMS.

- Annual buyer's guide with the most complete and accurate listing of products, services, manufacturers and distributors.

assays and opinions on the issues you face every day on the street, in the classroom and in your organization.
Photographs and artwork that explain and entertain.

- Interpretive reports on the current research.

- Regular columns on pediatric care, EKG interpretation, clinical questions and answers, new books and videos, and new products.

- Regular columns on quality assurance, instructor training, the public/private interface and legal issues.

To subscribe, please fill out the attached card.

If missing, please send a check for $\$ 21.97$ for a year's subscription (12 issues) to:

JEMS, P.O. Box 2789, Carlsbad, CA 92018 